\title{
Pemanfaatan Aplikasi Buku Tamu Berbasis Digital Pada Desa Arang Limbung Kabupaten Kuburaya
}

\author{
Riski Annisa', Sri Murni2 ${ }^{*}$, Panny Agustia Rahayuningsih ${ }^{3}$, Raja Sabarudin ${ }^{4}$ \\ ${ }^{1,3,4}$ Sistem Informasi Akuntansi Kampus Kota Pontianak, Universitas Bina Sarana Informatika, Indonesia \\ ${ }^{2 *}$ Sistem Informasi Kampus Kota Pontianak, Universitas Bina Sarana Informatika, Indonesia \\ Email: ${ }^{1}$ riski.rnc@bsi.ac.id, ${ }^{2 *}$ sri.six@bsi.ac.id, ${ }^{3}$ panny.par@bsi.ac.id, ${ }^{4}$ raja.rjd@ bsi.ac.id
}

\begin{abstract}
The progress of the development of computing and telecommunications has changed the way of life in the world in carrying out everyday activities. Desa Arang Limbung is the center of Government of Kubu Raya. In carrying out the duties of the government of development and society, the village head always coordinated with the community and other village institutions. To set the Village Head Meeting Schedule, a Guest Book Application The Role of the Guest Book is always limited to the administration, so it cannot be used as a benchmark to measure the level of village office services, because to use it further, the existing data must be summarized to produce information needed. The community service team conducts training using a digital guest book application that can be used to measure the number of visits at the village office while providing information about anyone in the village office which will be encountered by guests who come to the village office.
\end{abstract}

Keywords: Application, Guest Book, Village Office.

\begin{abstract}
Abstrak
Kemajuan perkembangan komputasi dan telekomunikasi telah mengubah cara hidup masyarakat di dunia dalam melakukan aktivitas sehari-hari. Desa Arang Limbung merupakan Pusat Pemerintahan Kabupaten Kubu Raya. Dalam melaksanakan tugas pemerintahan pembangunan dan kemasyarakatan, kepala desa senantiasa berkoordinasi dengan masyarakat serta lembaga desa lainnya. Untuk mengatur jadwal pertemuan kepala desa maka diperlukan sebuah aplikasi buku tamu Peran buku tamu selalu terbatas pada kelengkapan administrasi, sehingga tidak dapat dijadikan sebagai tolak ukur untuk mengukur tingkat pelayanan kantor desa, karena untuk menggunakannya lebih lanjut, data yang ada harus dirangkum untuk menghasilkan informasi yang dibutuhkan. Tim pengabdian masyarakat mengadakan pelatihan penggunaan sebuah aplikasi buku tamu digital yang dapat digunakan untuk mengukur jumlah kunjungan di kantor desa sekaligus menyediakan informasi mengenai siapa saja di kantor desa yang akan ditemui oleh tamu yang datang ke kantor desa.
\end{abstract}

Kata Kunci: Aplikasi, Buku Tamu, Kantor Desa.

\section{A. PENDAHULUAN}

Kemajuan perkembangan komputasi dan telekomunikasi telah mengubah cara hidup masyarakat di dunia dalam melakukan aktivitas sehari-hari. Keberadaan dan peran teknologi informasi dalam segala bidang kehidupan secara tidak sadar telah membawa dunia memasuki era baru globalisasi yang lebih cepat dari yang dibayangkan. Tidak berlebihan jika dikatakan bahwa perkembangan komputer telah membawa dunia ke era informasi. Di antara banyak sektor kehidupan manusia yang terkena dampak kehadiran teknologi informasi, organisasi adalah entitas yang paling diuntungkan (Mulyana \& Saepudin, 2019).

Desa Arang Limbung adalah salah satu kelurahan di kecamatan Sungai Raya kabupaten Kubu Raya. Desa Arang Limbung merupakan Pusat Pemerintahan Kabupaten Kubu Raya dan sebagai pintu gerbang masuknya wisatawan yang berkunjung ke Kubu Raya pada khususnya dan Kalimantan pada umumnya. Dalam melaksanakan tugas pemerintahan pembangunan dan kemasyarakatan, kepala desa senantiasa berkoordinasi dengan lembaga desa lainnya yaitu, BPD, LPMD, tokoh masyarakat, dan lain lain. Hal ini demi terlaksananya program-program yang disusun dan direncanakan dengan baik yang tertuang dalam Musrenbang maupun kegiatan teknis lainnya. 
Dalam melakukan koordinasi dengan beberapa lembaga terkait, kantor desa sering mengadakkan pertemuan dengan pihak-pihak terkait baik dilakukan di kantor desa maupun di luar kantor desa. Untuk mengatur jadwal pertemuan kepala desa maka diperlukan sebuah aplikasi buku tamu. Buku tamu merupakan alat untuk mengetahui berapa banyak tamu yang datang ke suatu tempat atau instansi. Penggunaan buku tamu pada dasarnya adalah untuk mencatat pengunjung atau siapa yang datang ke suatu tempat atau instansi (Mulyadi, 2019).

Buku tamu yang digunakan di kantor desa Arang Limbung berupa buku yang memuat identitas pengunjung seperti nomor registrasi, nama, tanggal hadir dan tanda tangan yang harus dilengkapi oleh setiap pengunjung. jumlah pengunjung, terjadi antrian panjang yang membuat pengunjung tidak nyaman dan beberapa pengunjung memilih untuk tidak mengisi buku tamu. Peran buku tamu selalu terbatas pada kelengkapan administrasi, sehingga tidak dapat dijadikan sebagai tolak ukur untuk mengukur tingkat pelayanan kantor desa, karena untuk menggunakannya lebih lanjut, data yang ada harus dirangkum untuk menghasilkan informasi yang dibutuhkan. Hal ini membuat kinerja aparat di kantor desa Arang LImbung menjadi tidak efisien. Penyimpanan data tamu menjadi kendala kinerja pegawai dalam mengumpulkan data tentang tamu yang sering datang karena penyimpanan data selalu terdapat dalam buku dan pencarian data tamu membutuhkan waktu yang lama, maka untuk mengatasi masalah tersebut, memerlukan aplikasi yang membantu mengelola data tamu dan menyimpan data secara lebih efektif dan efisien.

Terkait dengan uraian diatas, tim pengabdian masyarakat mengadakan pelatihan penggunaan sebuah aplikasi buku tamu digital yang dapat digunakan untuk mengukur jumlah kunjungan di kantor desa sekaligus menyediakan informasi mengenai siapa saja di kantor desa yang akan ditemui oleh tamu yang datang ke kantor desa. Pengabdian mayarakat ini bertujuan untuk menganalisa penggunaan buku tamu di Kantor Desa dan menganalisa kebutuhan sistem sebagai solusi atas permasalahan sistem.

\section{B. PELAKSAAN DAN METODE}

Adapun pelaksanaan yang dilakukan adalah dengan mengimplementasikan atau menerapkan pemberian buku tamu digital kepada pegawai kantor desa Arang Limbung sekaligus memberikan training sehingga aplikasi tersebut siap untuk dimanfaatkan dan digunakan. Impelementasi dan Pelatihan akan diberikan seminggu 1 kali setiap hari sabtu / minggu agar tidak menganggu kegiatan pegawai dan pengunjung dengan durasi 1 bulan melalui media online.

Pelaksanaan kegiatan program pengabdian kepada masyarakat "Pemanfaatan Aplikasi Buku Tamu Berbasis Digital Pada Desa Arang Limbung Kabupaten Kuburaya" menggunakan beberapa tahapan metode (Annisa dkk, 2020) sebagai berikut:

1. Tahap Survey

Dalam tahap ini melakukan survey lokasi kantor desa Arang Limbung dan pendataan jumlah pegawai yang ada di kantor desa Arang Limbung. Kemudian penentuan tanggal dan lokasi pelaksanaan kegiatan.

2. Tahap Persiapan

Dalam tahap ini melakukan observasi dan wawancara untuk mencari permasalahan yang terjadi pada objek pengabdian masyarakat serta merumuskan solusi san membuat proposal pengabdian masyarakat.

3. Tahap Sosialisasi

Dalam tahap ini dilakukan sosialisasi dan informasi mengenai kapan dan apa yang akan kami sampaikan dalam pelatihan

4. Tahap Pelatihan

Dalam tahap ini merupakan kegiatan inti dalam pengabdian kepada masyarakat yang terbagi menjadi 4 hari, susunan pelaksanan kegiatan sebagai berikut:

a. Hari pertama, pengenalan dan instalasi buku tamu digital,

b. Hari kedua, penjelasan fitur buku tamu digital,

c. Hari ketiga, pelatihan penggunaan buku tamu digital

d. Hari keempat, penyerahan modul dan master aplikasi

\section{HASIL DAN PEMBAHASAN}

Lokasi Kantor Desa Arang Limbung Kabupaten Kuburaya. Akses menuju kantor desa tersebut, menelusuri Ahmad Yani menuju jalan Arteri Supadio lalu ke jalan Angkasa Permai yang terletak di kabupaten Kuburaya menggunakan akses darat selama 19 menit dari Pontianak. Adapun jarak tempuh dari Universitasn Bina Sarana Informatika ke desa Arang Limbung adalah 11,1 KM. 


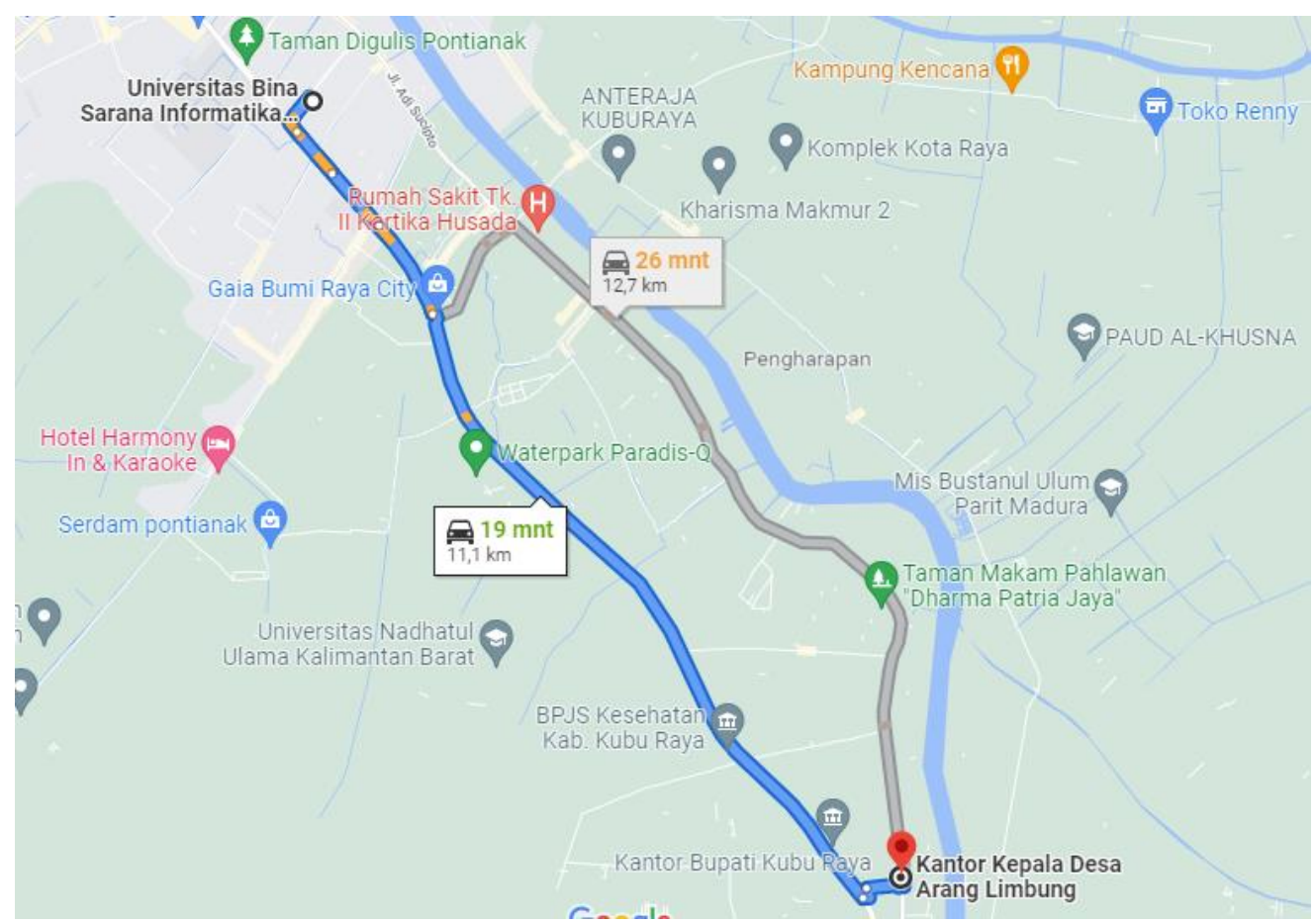

Gambar 1. Peta Jarak ke Lokasi Mitra

Pada tahap awal yaitu dilakukan survey lokasi mitra pengabdian masyarakat dan pendataan proses administrasi yang di lakukan kantor desa Arang Limbung Kabupaten Kuburaya. Kemudian didata jumlah peserta yang akan terlibat dalam pelatihan nantinya. Setelah itu tim pengabdian masyarakat melakukan observasi dan wawancara untuk mencari permasalahan yang terjadi pada objek pengabdian masyarakat serta merumuskan solusi dan membuat proposal pengabdian masyarakat. Dari hasil observasi yang dilakukan tim maka salah satu permasalahan dalam pendataan tamu yang akan bertemu dengan kepala desa ataupun pegawai yang ada pada kantor desa.

Kantor desa Arang Limbung merupakan salah satu instansi pemerintah desa yang ada di kabupaten Kuburaya, dimana lokasi kantor tidak jauh dari kota Pontianak dan memiliki fasilitas serta jangkauan internet sangat baik. Namun aktivitas pencatatan pengunjung pada buku tamu masih menggunakan proses konvensional, padahal intensitas pengunjung dalam 1 minggu berkisar antara 30 sampai 40 orang. Tentunya jika diakumulasi perbulan maka intensitas pengunjung berkisar 160 orang dan membutuhkan 8 halaman buku. Dilihat dari perhitungan ini, kantor desa membutuhkan banyak buku tamu pertahun dan sulit mencari informasi pengunjung sehingga tidak efektif dan efisien. Efisiensi terkait dengan lamanya waktu untuk pencarian data tamu atau pengunjung dan anggaran yang diperlukan dalam pengadaan buku tamu. Sedangkan efektifitas terkait dengan penyimpanan data tamu yang masih dituangkan dalam buku dan membutuhkan tempat yang luas untuk pengarsipan buku tamu.

Untuk mencapai hasil maksimal dan efisien, maka harus dilakukan perubahan pada buku tamu di Kantor Desa Arang Limbung Kabupaten Kuburaya. Dengan cara membuat program aplikasi dimana pengunjung yang 54omput ke Kantor Desa Arang Limbung Kabupaten Kuburaya tidak lagi mengisi buku tamu secara konvensional, tapi petugas bisa langsung mengisikan secara langsung data kunjungan pada aplikasi yang sudah ada dalam 54omputer. Apabila pimpinan Kantor Desa Arang Limbung Kabupaten Kuburaya meminta rekapan data pengunjung. Maka pegawai yang bertugas bisa langsung mencetak laporan buku tamu pada Aplikasi Buku Tamu Digital.

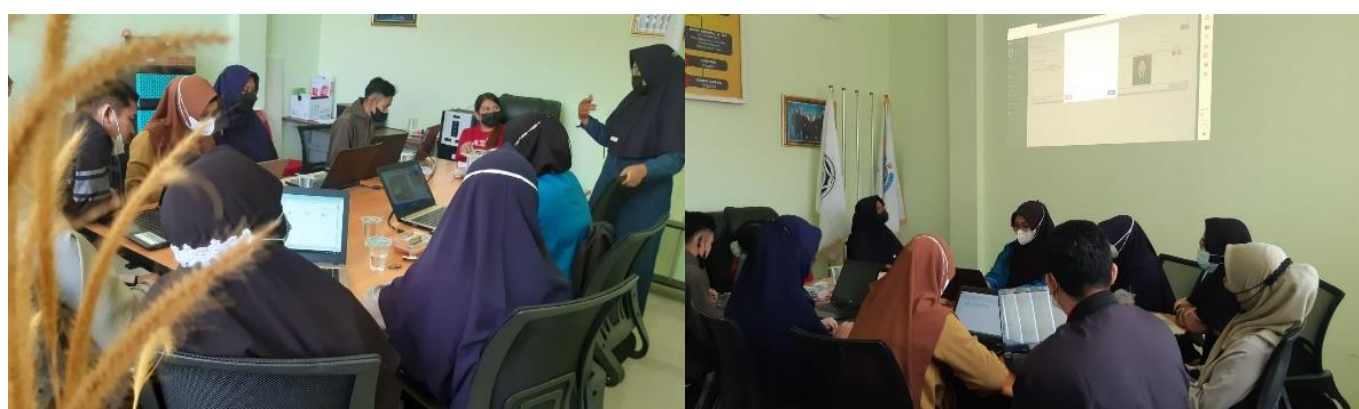

Gambar 2. Kegiatan pelatihan berlangsung 
Aplikasi buku tamu digital yang di sosialisasikan menyediakan 2 level akses pengguna, yaitu admin dan operator. Yang membedakan keduanya adalah di menu admin terdapat data user dan laporan. Aplikasi hanya membahas tentang buku tamu dimana aktivitas yang ada seperti aktivitas tamu yang masuk dan keluar beserta detail lamanya pertemuan antara tamu yang bersangkutan dengan pejabat yang ditemui serta adanya Whatsapp Blast yang digunakan untuk menginformasikan kepada tamu apabila pejabat yang akan ditemui telah berada di Kantor. Penyimpanan data tamu berada dalam database SQL server. Supaya aplikasi bisa diterapkan pada Kantor desa, diharapkan aplikasi terhubung dengan jaringan internet agar fitur pemberitahuan melalui aplikasi media sosial Whatsapp bisa berjalan dengan baik.

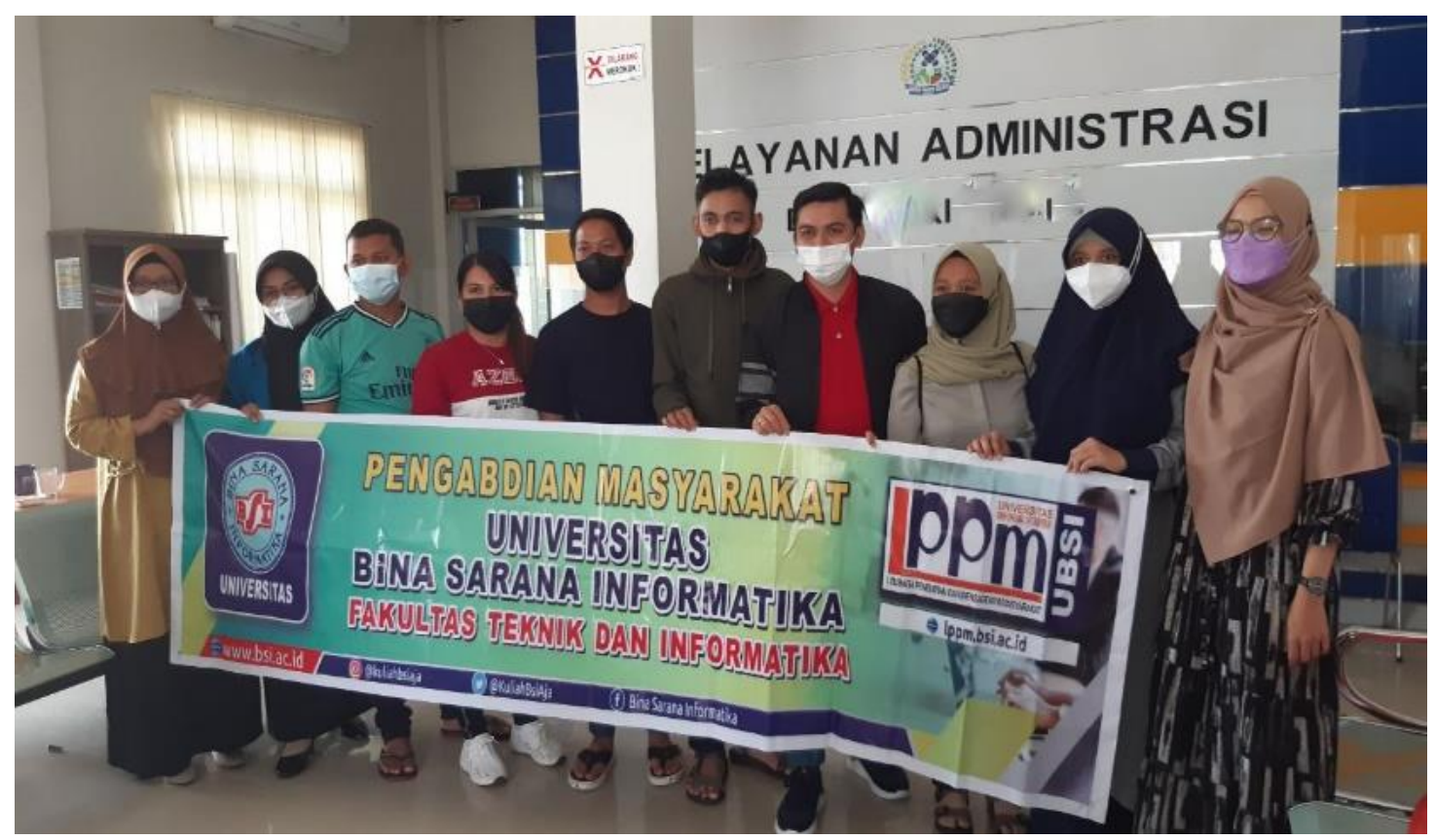

Gambar 3. Foto Bersama Peserta Pelatihan

\section{PENUTUP}

\section{Kesimpulan}

Dari hasil pelaksanaan kegiatan pengabdian masyarakat dengan teman pemanfaatan aplikasi buku tamu digital pada kantor desa Arang Limbung Kabupaten Kuburaya tebagi menjadi beberapa tahapan metode pengabdian masyarakat yaitu dengan cara survey lokasi dan mitra pengabdian, kemudian persiapan data, selanjutnya sosialisasi kepada mitra mengenai materi serta pembuatan proposan, dan yang terakhir tahapan pelatihan yang dijadwalkan selama 4 (empat hari). Sebelumnya pada kantor Desa Arang Limbung proses pencatatan atau pemberitahuan info tamu masih dilakukan secara manual kini sudah bisa diterapkan aplikasi buku tamu digital untuk mempermudah dalam mengukur jumlah kunjungan di kantor desa sekaligus menyediakan informasi mengenai siapa saja di kantor desa yang akan ditemui oleh tamu yang datang ke kantor desa.

\section{Saran}

Dalam pengembangan Aplikasi Buku tamu Berbasis Digital pada Kantor Desa Nusapati Kabupaten Kabupaten Kuburaya, dapat diajukan beberapa saran, yaitu :

1. Aplikasi ini mampu dikembangkan lagi menggunakan memberi batasan yg lebih kompleks dan sinkron menggunakan kebijakan Kantor Desa Arang Limbung Kabupaten Kubu Raya.

2. Aplikasi ini bisa diterapkan untuk Kantor-kantor Desa yang ada di Kabupaten Kuburaya.

\section{Ucapan Terima Kasih}

Terima kasih kepada Universitas Bina Sarana Informatika dan Kantor Desa Arang Limbung sebagai mitra pengabdian masyarakat ini serta pihak-pihak yang terlibat dalam penyelenggaraan kegiatan pengabdian masyarakat ini.

\section{E. DAFTAR PUSTAKA}

Mulyana, E., \& Saepudin, A. (2019). Perkembangan Dan Pemanfaatan Teknologi Informasi Dalam Penyelenggaraan Pendidikan Jarak Jauh. Jurnal Teknodik, 119-134. 
Mulyadi, M. (2019). Aplikasi Buku Tamu Elektronik Pada Perpustakaan STIKOM Dinamika Bangsa. IJCIT (Indonesian Journal on Computer and Information Technology), 4(1).

Pemerintah Desa Arang Limbung [editorial]. 2021. Retrieved from https://desaaranglimbung.com

Rahayuningsih, P. A. (2020). Pemanfaatan Digital Kufi Dalam Meningkatkan Technopreneurship Pada Organisasi Prisma. WIDYA LAKSANA, 9(2), 213-216.

Wikipedia. $\quad$ (n.d.). $\quad$ Retrieved $\quad$ from https://id.wikipedia.org/wiki/Arang_Limbung,_Sungai_Raya,_Kubu_Raya 